\title{
Constructive Empiricism: Normative or Descriptive?
}

\author{
Moti Mizrahi \\ Forthcoming in International Journal of Philosophical Studies
}

\begin{abstract}
In this paper, I argue that Constructive Empiricism (CE) is ambiguous between two interpretations: $\mathrm{CE}$ as a normative epistemology of science and $\mathrm{CE}$ as a descriptive philosophy of science. When they present CE, constructive empiricists write as if CE is supposed to be more than a normative epistemology of science and that it is meant to be responsible to actual scientific practices. However, when they respond to objections, constructive empiricists fall back on a strictly normative interpretation of $\mathrm{CE}$. This ambiguity seems to make $\mathrm{CE}$ immune to objections in a rather ad hoc fashion.
\end{abstract}

Keywords: Bas van Fraassen; constructive empiricism; inference to the best explanation; observable; scientific realism; voluntarist epistemology

\section{Introduction}

Roughly speaking, constructive Empiricism (CE) is the view that scientific theories "save the phenomena." More precisely, as far as theories are concerned, constructive empiricists recommend suspending belief with respect to the existence of unobservable entities, events, or processes. As van Fraassen (1980, p. 12) puts it, CE is the view that "Science aims to give us theories that are empirically adequate; and acceptance of a theory involves as belief only that it is empirically adequate." For van Fraassen (1980, p. 18), "to accept a theory is (for us) to believe 
that it is empirically adequate - that what the theory says about what is observable (by us) is true."

CE is supposed to be an alternative to scientific realism. Usually, scientific realism is taken to include one or more of the following theses (Psillos 2006, p. 135):

The Metaphysical Thesis: The world has a definite and mind-independent structure. The Semantic Thesis: Scientific theories are truth-conditioned descriptions of their intended domain. Hence, they are capable of being true or false. The theoretical terms featuring in theories have putative factual reference. So if scientific theories are true, the unobservable entities they posit populate the world.

The Epistemic Thesis: Mature and predictively successful scientific theories are wellconfirmed and approximately true. So entities posited by them, or, at any rate entities very similar to those posited, inhabit the world. (Cf. Psillos 1999)

Accordingly, scientific realists say that a belief in the approximate truth of mature science's best theories is warranted, whereas constructive empiricists say that a more modest attitude is appropriate, namely, one of "acceptance" rather than belief. To "accept" a theory, according to van Fraassen, is to believe that the theory's claims about the observable are true and to remain agnostic regarding its claims about the unobservable.

In other words, according to van Fraassen (2010, pp. 547-548), “scientific realism is in the first place a view that characterizes science in terms of an aim, a criterion of success." For scientific realists the criterion of success is truth (or approximate truth), whereas for constructive empiricists the criterion of success is empirical adequacy. However, the claim that "Science aims 
to give us theories that are empirically adequate" (van Fraassen 1980, p. 18) is ambiguous between a normative interpretation and a descriptive interpretation. According to the former, it means that science ought to aim to give us empirically adequate theories. According to the latter, it means that science does in fact aim to give us empirically adequate theories. That is, CE is ambiguous between a normative interpretation (NCE) and a descriptive interpretation (DCE):

(NCE) Empirical adequacy ought to be science's criterion of success.

(DCE) Empirical adequacy is science's criterion of success.

Now, constructive empiricists sometimes write as if $\mathrm{CE}$ is supposed to be not merely a normative epistemology of science but rather a descriptive philosophy of science. Here is some textual evidence for (DCE) (emphasis added unless otherwise noted):

Acceptance of theories [...] is a phenomenon of scientific activity (van Fraassen 1980, p. 12).

Scientific realism and constructive empiricism are, as I understand them, not epistemologies but views of what science is. Both views characterize science as an activity with an aim — a point, a criterion of success — and construe (unqualified) acceptance of science as involving the belief that science meets that criterion. According to scientific realism the aim is truth (literally true theories about what things are like). Constructive empiricism sees the aim as not truth but empirical adequacy (van Fraassen 1998, p. 213). 
Like the interpretation of any human activity, $[\mathrm{CE}]$ is constrained by the "text" of the scientific activity it interprets. Within those constraints, it succeeds or fails according to its ability to provide an interpretation of science that contributes to our understanding of science, making intelligible to us various elements of its practice (Monton and Mohler 2012).

Any philosophical view of science is to be held accountable to actual scientific practice, scientific activity (van Fraassen 1994, p. 184).

Constructive Empiricism, the view introduced in The Scientific Image, is a view of science, and answer to the question 'what is science?' (van Fraassen 2001, p. 151).

This textual evidence suggests a descriptive interpretation of CE along the lines of (DCE). The problem is that, when they defend CE from objections, constructive empiricists fall back on a strictly normative interpretation of $\mathrm{CE}$ along the lines of (NCE).

Even critics of CE are not always careful to distinguish between (NCE) and (DCE). For example, according to Asay (2009, p. 423), constructive empiricists "claim to offer an adequate reconstruction of the aim and practice of scientific inquiry, all without adopting some of the more substantive ontological and theoretical commitments of scientific realism" (emphasis added). A reconstruction, of course, is a normative notion (Lakatos 1970, pp. 91-136), especially if the motivation for offering a rational reconstruction is epistemic modesty. ${ }^{1}$ But then Asay

\footnotetext{
${ }^{1}$ Lakatos (1970, p. 91) argues that "any rational reconstruction of history needs to be supplemented by an empirical (socio-psychological) 'external history'."
} 
(2009, p. 423) goes on to say that "The goal of scientific practice, according to the constructive empiricist, is not to produce true theories but rather to produce empirically adequate theories" (emphasis added). To claim that the goal of an enterprise is $X$ is to make a factual claim about that enterprise. The claim that the goal of science is empirical adequacy is a descriptive claim about actual scientific practice, not a normative claim about how science ought to be (or a rational reconstruction of science). Failure to carefully distinguish between normative and descriptive claims about science, as far as CE is concerned, has allowed constructive empiricists to evade serious objections, or so I argue.

In this paper, then, I argue that the ambiguity between (NCE) and (DCE) makes CE immune to objections in a rather ad hoc fashion. To make this case, I rely on textual evidence. I discuss two well-known objections against $\mathrm{CE}$ and how constructive empiricists respond to these objections. The first objection concerns the constructive empiricist's observable/unobservable distinction. The second objection concerns the use of Inference to the Best Explanation (IBE) in scientific practice. I show that these objections to CE are meant to be objections against (DCE). What constructive empiricists say in response to these objections, however, amounts to a defense of (NCE), not (DCE), or so I argue.

Rosen (1994) has already pointed out that CE is ambiguous between a descriptive interpretation and a normative interpretation. However, I think that the ambiguity I point to in this paper is different from the one Rosen (1994) identified. Here is why. Following van Fraassen, Rosen (1994, p. 144) characterizes Constructive Empiricism and Scientific Realism as follows (original emphasis): 
(SR) Science aims to give us, in its theories, a literally true story of what the world is like; and acceptance of a scientific theory involves the belief that it is true. This is the correct statement of scientific realism (van Fraassen 1980, p. 8; 1989, p. 191).

(CE) Science aims to give us theories which are empirically adequate, and acceptance of a theory involves as belief only that it is empirically adequate. This is the statement of the antirealist position I advocate. I shall call it constructive empiricism (van Fraassen 1980, p. 12; 1989, p. 192).

Since "Van Fraassen's language is always descriptive," Rosen (1994, p. 148) argues, a "literal interpretation of [van Fraassen's] texts would therefore have it that SR and CE are opposing proposals about what scientists actually think" (emphasis added). Rosen (1994, p. 147) rejects this interpretation because he thinks that it would make "The Scientific Image [...] a work of inept sociology." So Rosen (1994, p. 147) considers a normative interpretation of CE according to which "CE is a prescription for the intentions [scientists] ought to have" (original emphasis). But Rosen (1994, p. 148) rejects this interpretation as well and concludes that " $C E$ is neither a straightforward description of the intentional features of science nor a proposal for revising them" (original emphasis). He then goes on to offer a fictionalist reading of CE.

For present purposes, however, the important point is that, no matter how one construes 'aims' in CE, the further question as to whether the claim about the aim of science is descriptive or prescriptive still remains. In other words, whether or not the actual intentions of scientists determine the aim of science, that aim, whatever it is, can still be understood either as the actual aim of science or as an ideal. For this reason, van Fraassen's (1994) reply to Rosen (1994) does 
not address the ambiguity between (DCE) and (NCE). In his reply to Rosen (1994), van Fraassen distinguishes between $\mathrm{CE}$ and the following theses:

CE/R: it is not the case that SR/R [i.e., (all or most) scientists aim to construct true theories, and believe the theories they accept to be true], but (all or most) real scientists aim to construct empirically adequate theories, and believe the theories they accept to be empirically adequate (van Fraassen 1994, p. 181).

$\mathrm{CE} / \mathrm{U}$ : the conscious understanding of (all or most) scientists is that the aim of science is to produce empirically adequate theories (van Fraassen 1994, p. 187).

Van Fraassen (1994) says that "Neither CE/U nor CE/R is to be equated with CE" (p. 188), which is the thesis "that the aim of science is to give us empirically adequate theories" (p. 185). Although this may adequately resolve the ambiguity Rosen (1994) identifies between what the aims of individual scientists actually are and what the aim of science as a collective enterprise is, it does not resolve the ambiguity between (DCE) and (NCE). Even if we join van Fraassen in rejecting Rosen's (1994) “equation of the intentional aspects of science with the intentions and opinions of the scientists" (van Fraassen 1994, p. 181), there remains the question of whether "the scientist [actually] pursues empirical adequacy rather than truth" or "the scientist [ought to] pursue empirical adequacy rather than truth" (van Fraassen 1994, p. 181).

With these clarifications in hand, I argue that the ambiguity between (NCE) and (DCE) makes CE immune to objections in a rather ad hoc fashion. Here is how I plan to proceed. In Section 2, I discuss a well-known objection against the constructive empiricist's 
observable/unobservable distinction in order to show that the objection is supposed to be an objection to (DCE), whereas the responses that constructive empiricists offer amount to a defense of (NCE). In Section 3, I discuss another well-known objection against CE that concerns the use of Inference to the Best Explanation (IBE) in scientific practice. I show that this objection, too, is meant to be an objection against (DCE), whereas what constructive empiricists say in response to this objection amounts to a defense of (NCE). I conclude that constructive empiricists face the following dilemma: admit that $\mathrm{CE}$ is just a normative epistemology, not a view of what science is, or acknowledge the serious objections that were leveled against CE.

\section{The Observable/Unobservable Distinction}

Starting with Maxwell (1962), who was probably the first to point out that 'is observable' is a vague predicate, others have argued that there is no principled way of drawing a distinction between what is observable and what is unobservable. For example, Churchland argues that the observable/unobservable distinction "is only very feebly principled and is wholly inadequate to bear the great weight that van Fraassen puts on it" (1985, p. 40). Similarly, according to Hacking (1985, pp. 146-147):

I know that what I see through the microscope is veridical because we made the grid to be just that way. I know that the process of manufacture is reliable, because we can check the results with the microscope. Moreover we can check the results with any kind of microscope, using any of a dozen unrelated physical processes to produce an image. Can we entertain the possibility that, all the same, this is some gigantic coincidence? 
More recently, Teller (2001, pp. 132-134) argues that what counts as observable also includes objects viewed through optical microscopes. $^{2}$

For present purposes, what is of interest is the way in which constructive empiricists respond to these objections concerning the observable/unobservable distinction. The critics object that there is no principled distinction to be applied to actual scientific practices, such as observations by means of optical microscopes, whereas constructive empiricists respond that the distinction is a normative epistemic standard. In other words, the critics object to (DCE), whereas constructive empiricists defend (NCE). To illustrate, van Fraassen (1980, p. 16) says that " $\mathrm{X}$ is observable if there are circumstances which are such that, if $\mathrm{X}$ is present to us under those circumstances, then we observe it" and insists that this "is not meant as a definition, but only as a rough guide to the avoidance of fallacies" (emphasis added). A "guide to the avoidance of fallacies," however, is a normative standard, i.e., it tells us how we ought to reason in order to avoid making mistakes in reasoning, not how we actually do reason.

In a later work, van Fraassen (2001, pp. 158-160) argues that, by looking through a microscope, we detect, but do not observe, a paramecium. As van Fraassen (2001, p. 158) writes:

The microscope's output can be sent into a scanner which transmits to a computer or projector - then we see the paramecia on the wall or the monitor. We are having a different sort of experience then, for we say after only a little urging that we are seeing an image. [...] I submit that without stretching ourselves very far, we can report on our sightings through a microscope in the same way that we report our rainbow-observations.

\footnotetext{
${ }^{2}$ See also Alspector-Kelly (2004), Muller (2004), Contessa (2006), Dicken and Lipton (2006), and Muller and van Fraassen (2008).
} 
[...] Rainbows are not objects, events or processes. [...] I think we can relate to our experiences with microscopes in the same way [i.e., as public hallucinations].

For van Fraassen, this means that we should think of our microscopic observations in the same way that we think of our observations of rainbows, namely, as "public hallucinations." Again, however, this reply amounts to a defense of (NCE), for van Fraassen tells us how we should think of microscopic observations in order to be agnostics about unobservables. But that is not what the critics of CE are objecting to. The critics of CE are objecting to (DCE), not (NCE), for they claim that scientists are reasonable in believing that what they see through a microscope is not a "public hallucination" but rather a microscopic object.

Similarly, vis-à-vis objections to the observable/unobservable distinction, Muller (2004, p. 85) says the following:

In all interesting cases of unobservables that occur in accepted scientific theories, the objects are unambiguously unobservable (electrons, forces, gluon-fields, black holes, tauneutrino's, superstrings, and so forth), which makes the case of ambiguous unobservables largely 'academic' (in its pejorative sense).

To say that alleged cases of "ambiguous unobservables" are "largely 'academic' (in the pejorative sense)" is to say that we should not worry about such cases. But again, that amounts to a defense of (NCE), which is not what the critics of CE are objecting to. The critics' objections are meant to be objections against (DCE) (see, e.g., Hacking 1985). 


\section{Inference to the Best Explanation (IBE)}

Another well-known objection to CE stems from the fact that van Fraassen is critical of Inference to the Best Explanation (IBE). ${ }^{3}$ According to van Fraassen (1980, p. 87):

When a theory is advocated, it is praised for many features other than empirical adequacy and strength: it is said to be mathematically elegant, simple, of great scope, complete in certain respects: also of wonderful use in unifying our account of hitherto disparate phenomena, and most of all, explanatory.

For constructive empiricists, superempirical virtues, such as simplicity, are merely pragmatic virtues, irrelevant to a theory's truth. In other words, for constructive empiricists, IBE is a form of inference that is not truth-conducive. As van Fraassen (1980, p. 143) writes:

[IBE] is a rule that selects the best among the historically given hypotheses. We can watch no contest of the theories we have so painfully struggled to formulate, with those no one has proposed. So our selection may well be the best of a bad lot.

Similarly, according to Muller (2008, p. 143):

[An inference] going from observable behavior to unobservable mental states, smacks too much of an Inference-to-the-Best-Explanation (IBE), which is a mode of inference that Van Fraassen is very critical about, in particular when it concerns an explanandum about observables only and an explanans which is also about unobservable.

\footnotetext{
${ }^{3}$ For van Fraassen's objections against IBE, see (1983), sec. 2; (1985), p. 280; (1989), p. 143-144 and p. 192.
} 
The problem is that IBE "seems ubiquitous in scientific practice" (Chakravartty 2013). ${ }^{4}$ Here is an example of IBE in scientific practice. According to Cann, et al. (1987, p. 33):

We infer from the tree of minimum length [a genealogical tree for 134 types of human mtDNA] that Africa is a likely source of the human mitochondrial gene pool. This inference comes from the observation that one of the two primary branches leads exclusively to African mtDNAs [...] while the second primary branch also leads to African mtDNAs [...]. By postulating that the common ancestral mtDNA $[\ldots]$ was African, we minimize the number of intercontinental migrations needed to account for the geographic distribution of mtDNA types. It follows that $\mathrm{b}$ is a likely common ancestor of all non-African and many African mtDNAs (my emphasis). ${ }^{5}$

This passage suggests that $b$ is a theoretical posit whose existence is postulated on superempirical grounds, such as simplicity, to account for mtDNA data. In other words, the reasoning here seems to be the following (Psillos 2007a, pp. 442-443):

1. One of the two primary branches of the tree of minimum length leads exclusively to African mtDNAs, whereas the second primary branch also leads to African mtDNAs.

2. The best (i.e., simplest) explanation for (1) is that the common ancestral mtDNA was African.

3. No other explanation explains (1) as well as (2) does.

\footnotetext{
${ }^{4}$ On IBE in evolutionary psychology, see Holcomb (1996). On IBE and climate models, see Katzav (2013). See also Bird (1998, pp. 173-175) and the introduction in Lipton (2004).

${ }^{5}$ For more on the Mitochondrial Eve hypothesis, see Sykes (2001).
} 
4. Therefore, (2) (i.e., the common ancestral mtDNA was African).

In reply, constructive empiricists have argued that, at the end of the day, the key commitment of the relevant inferences is to the empirical adequacy of hypotheses such as the Mitochondrial Eve hypothesis. Why? Because IBE might lead us to believe the best hypothesis of a bad lot (van Fraassen 1989, p. 143) and it is a priori implausible to think that scientists are epistemically privileged insofar as they are predisposed to hit upon the best explanation (van Fraassen 1989, p. 144).

As a reply to the objection that IBE "seems ubiquitous in scientific practice"

(Chakravartty 2013), however, these considerations will not do, for they amount to a defense of (NCE), not (DCE). That is to say, constructive empiricists argue that we should not infer the truth of a hypothesis from the fact that it provides the best explanation for a phenomenon. Rather, from the fact that a hypothesis provides the best explanation for a phenomenon, we should infer that it is empirically adequate. But this is a normative claim that amounts to a defense of (NCE), not (DCE). Even if constructive empiricists are right that we should be committed to the empirical adequacy of a hypothesis, not to its (approximate) truth, this reply does not address the objection that IBE "seems ubiquitous in scientific practice" (Chakravartty 2013). In other words, the question posed to CE by the ubiquity of IBE is not "Should we be committed to the (approximate) truth (or empirical adequacy) of hypotheses that provide the best explanation for phenomena?" but rather "Does CE explain the ubiquity of IBE in scientific practice?" As far as I can tell, constructive empiricists haven't offered an answer to the latter question, which is not surprising, of course, given their objections to IBE. But that is precisely the problem. 
Although there is some debate as to whether or not van Fraassen's voluntarist epistemology informs $\mathrm{CE},{ }^{6}$ constructive empiricists might wish to appeal to his voluntarist epistemology and argue that the question about the aim of science is a question of is/can, not is/ought. That is, on van Fraassen's voluntarist epistemology, rationality is not about what one is epistemically obligated to believe. Rather, for van Fraassen (1989, pp. 171-173; 2000, p. 277; 2002, p. 92), one is rationally entitled to believe anything that one is not compelled to disbelieve. In other words, for van Fraassen $(1989$, p. 157), one can rationally believe anything that does not sabotage its own possibility of vindication (1985, p. 248).

Even if we grant van Fraassen that his voluntarist framework is a viable epistemology (cf. Kvanvig 1994), ${ }^{7}$ appealing to it does nothing to resolve the ambiguity between (DCE) and (NCE). In fact, it only makes matters worse. For, even if rationality is a matter of permission, not obligation, as van Fraassen claims, CE is still ambiguous between the following interpretations:

(DCE) Empirical adequacy is science's criterion of success.

(VCE) Empirical adequacy can be science's criterion of success.

In other words, we are still left with the question of whether "the scientist [actually] pursues empirical adequacy rather than truth" or "the scientist [is rationally entitled to] pursue empirical adequacy rather than truth" (van Fraassen 1994, p. 181). Even if "the scientist [actually] pursues

\footnotetext{
${ }^{6}$ According to Psillos (2007b, p. 135), van Fraassen's "views on rationality are quite independent from his views on constructive empiricism." Cf. Dicken (2009, p. 191), who argues that "van Fraassen's articulation and defense of constructive empiricism makes an ineliminable appeal to his voluntarist framework," which is a vice, not a virtue of CE (2009, p. 197).

${ }^{7}$ See also Dicken (2009). Just as "there is something epistemologically unsatisfactory in being told by Muller and van Fraassen that the constructive empiricist can maintain [an observable/unobservable] distinction on no stronger grounds than that if he is to be a constructive empiricist, he must maintain such a distinction" (Dicken 2009, p. 193), there is something epistemologically unsatisfactory in being told by constructive empiricists that they can appeal to van Fraassen's voluntarist epistemology on no stronger grounds that than if they are to be constructive empiricists, they must appeal to it.
} 
empirical adequacy rather than truth," that doesn't necessarily mean that "the scientist [is rationally entitled to] pursue empirical adequacy rather than truth" (van Fraassen 1994, p. 181). Likewise, even if "the scientist [is rationally entitled to] pursue empirical adequacy rather than truth," that does not necessarily mean that "the scientist [actually] pursues empirical adequacy rather than truth" (van Fraassen 1994, p. 181).

At this point, one might even think that (VCE) itself admits of at least two distinct interpretations:

(VCE1) Empirical adequacy can be the criterion of success of (all or most) scientists. (VCE2) Empirical adequacy can be the criterion of success of the scientific enterprise.

This is, in essence, the ambiguity that Rosen (1994) exposed. Given van Fraassen's remarks about chess $(1980$, p. $8 ; 1989$, p. 189; 1994, p. 180), however, I think it is safe to rule out (VCE1). Even so, CE is still ambiguous between (DCE) and (VCE2).

Accordingly, (DCE) and (VCE) are clearly distinct interpretations of CE. If CE is (VCE), or more precisely (VCE1), then, pace van Fraassen (1994, p. 186), CE is not an adequate response to the question "what is science?" (original emphasis). It may be an answer to the question what science can be, but not what science is. On the other hand, if CE is (DCE), then constructive empiricists haven't adequately addressed the aforementioned objections concerning the observable/unobservable distinction and IBE, since we can substitute (NCE) for (VCE) in Sections 2 and 3 and the complaints will still stand, namely, that constructive empiricists offer normative responses to descriptive objections. In the case of the observable/unobservable distinction, to say that one is rationally entitled to suspend judgment about unobservables is not 
an adequate reply to the objection that the observable/unobservable distinction is unprincipled (cf. Dicken 2009). Similarly, to say that one is rationally entitled to suspend judgment about conclusions arrived at by using IBE is hardly an adequate response to the objection that IBE "seems ubiquitous in scientific practice" (Chakravartty 2013).

\section{Conclusion}

If the aforementioned considerations are correct, then $\mathrm{CE}$ is ambiguous between (NCE) and (DCE). The problem is that constructive empiricists sometimes write as if CE is supposed to be a descriptive philosophy of science along the lines of (DCE), and that it is meant to be responsible to actual scientific practices (see textual evidence cited in Section 1), but when they reply to objections, constructive empiricists fall back on a strictly normative interpretation of CE along the lines of (NCE) (see textual evidence cited in Sections 2 and 3). This ambiguity seems to make CE immune to objections in a rather ad hoc manner.

If this is correct, then constructive empiricists are forced into the following dilemma. On the one hand, if CE is to be interpreted normatively, along the lines of (NCE) or (VCE), then, pace van Fraassen (2001, p. 151), CE is not an answer to the question what science is. Perhaps $\mathrm{CE}$ is an answer to the question what science ought to be or what science can be, but not what science $i s$. This is a problem for constructive empiricists for the following reasons. First, as Iranzo (2002, p. 335) puts it, "theoretical agnosticism could hardly motivate scientists to focus just on the observational consequences derived from the theory at issue." ${ }^{\prime 8}$ In other words, it is not obvious how empirical adequacy as an ideal or rationally permissible aim can actually motivate scientists to test the empirical consequences of their theories. Second, if CE is (NCE),

\footnotetext{
${ }^{8}$ Iranzo (2002, p. 335) concludes that, "concerning scientific practice, realist beliefs cannot be considered as a gratuitous surplus which should be rejected." In this paper, I do not wish to defend scientific realism, but just to make the modest point that $\mathrm{CE}$ is ambiguous between descriptive and prescriptive interpretations.
} 
then it is difficult to see how a normative theory, such as (NCE), can account for actual scientific practices. ${ }^{9}$ At any rate, if CE is (NCE) or (VCE), then, pace van Fraassen (1998, p. 213), CE is just a normative epistemology, voluntarist or otherwise, not a view of what science is.

On the other hand, if CE is (DCE), then the replies constructive empiricists have offered thus far in response to the aforementioned objections (namely, that the observable/unobservable distinction is unprincipled and that IBE is ubiquitous in scientific practice) are unsatisfactory. These responses are unsatisfactory because they amount to a defense of (NCE), not (DCE), whereas the objections are supposed to be objections to (DCE). This is a problem for constructive empiricists because it undermines van Fraassen's (1980, p. 73) claim that CE "makes better sense of science, and of scientific activity," than scientific realism does (emphasis added).

\section{Acknowledgments}

I am grateful to an anonymous reviewer of International Journal of Philosophical Studies for helpful comments on earlier drafts.

\section{References}

Alspector-Kelly, M. (2004). Seeing the Unobservable: Van Fraassen and the Limits of Experience. Synthese, 140, 331-353.

Asay, J. (2009). Constructive Empiricism and Deflationary Truth. Philosophy of Science, 76, 423-443.

Bird, A. (1998). Philosophy of Science. University College London Press.

\footnotetext{
${ }^{9}$ Furthermore, if CE is (NCE), it is not obvious how CE can combine with van Fraassen's (1980, p. 40) evolutionary analogy to explain predictive success. See also Rowbottom (2010).
} 
Cann, R. L., Stoneking, M., \& Wilson, A. C. (1987). Mitochondrial DNA and Human Evolution. Nature, 325, 31-36.

Chakravartty, A. (2013). Scientific Realism. In E. N. Zalta (Ed.), The Stanford Encyclopedia of Philosophy (Summer 2013 Edition). http://plato.stanford.edu/entries/scientific-realism/.

Churchland, P. M. (1985). The Ontological Status of Unobservables: In Praise of the Superempirical Virtues. In P. M. Churchland \& C. A. Hooker (Eds.), Images of Science: Essays on Realism and Empiricism, with a Reply from Bas C. van Fraassen (pp. 35-47). Chicago: University of Chicago Press.

Contessa, G. (2006). Constructive Empiricism, Observability, and Three Kinds of Ontological Commitment. Studies in History and Philosophy of Science, 37, 454-468.

Dicken, P., \& Lipton, P. (2006). What can Bas Believe? Musgrave and van Fraassen on Observability. Analysis, 66, 226-233.

Dicken, P. (2009). Constructive Empiricism and the Vices of Voluntarism. International Journal of Philosophical Studies, 17, 189-201.

Hacking, I., (1985). Do We See Through a Microscope? In P. M. Churchland \& C. A. Hooker (Eds.), Images of Science: Essays on Realism and Empiricism, with a Reply from Bas C. van Fraassen (pp. 132-152). Chicago: University of Chicago Press.

Holcomb, H. R. (1996). Just So Stories and Inference to the Best Explanation in Evolutionary Psychology. Minds and Machines, 6, 525-540.

Iranzo, V. (2002). Constructive Empiricism and Scientific Practice: A Case Study. Theoria, 17, 335-357.

Katzav, J. (2013). Hybrid Models, Climate Models, and Inference to the Best Explanation. British Journal for the Philosophy of Science, 64, 107-129. 
Kvanvig, J. L. (1994). A Critique of van Fraassen's Voluntaristic Epistemology. Synthese, 98, 325-348.

Lipton, P. (2004). Inference to the Best Explanation. $2^{\text {nd }}$ Ed. London: Routledge.

Maxwell, G. (1962). The Ontological Status of Theoretical Entities. In H. Feigl \& G. Maxwell (Eds.), Scientific Explanation, Space, and Time: Minnesota Studies in the Philosophy of Science (Vol. 3, pp. 3-27). Minneapolis: University of Minnesota Press.

Monton, B. (Ed.). (2007). Images of Empiricism: Essays on Science and Stances, with a Reply from Bas C. van Fraassen. New York: Oxford University Press.

Monton, B. \& Mohler, C. (2012). Constructive Empiricism. In E. N. Zalta (Ed.), The Stanford Encyclopedia of Philosophy (Winter 2012 Edition). http://plato.stanford.edu/entries/constructive-empiricism/.

Muller, F. A. (2004). Can a Constructive Empiricist Adopt the Concept of Observability? Philosophy of Science, 71, 80-97.

Muller, F. A. (2008). In Defence of Constructive Empiricism: Maxwell's Master Argument and Aberrant Theories. Journal for General Philosophy of Science, 39, 131-156.

Muller, M. A., \& van Fraassen, B. C. (2008). How to Talk about Unobservables. Analysis, 68, 197-205.

Psillos, S. (1999). Scientific Realism: How Science Tracks Truth. London: Routledge.

Psillos, S. (2006). Thinking about the Ultimate Argument for Realism. In C. Cheyne and J. Worrall (Eds.), Rationality \& Reality: Essays in Honour of Alan Musgrave (pp. 133-156). Dordrecht: Springer.

Psillos, S. (2007a). The Fine Structure of Inference to the Best Explanation. Philosophy and Phenomenological Research, 74, 441-448. 
Psillos, S. (2007b). Putting a Bridle on Irrationality: An Appraisal of van Fraassen's New Epistemology. In B. Monton (Ed.), Images of Empiricism: Essays on Science and Stances, with a Reply from Bas C. van Fraassen (pp. 134-164). New York: Oxford University Press.

Rosen, G. (1994). What is Constructive Empiricism? Philosophical Studies, 74, 143-178.

Rowbottom, D. P. (2010). Evolutionary Epistemology and the Aim of Science. Australasian Journal of Philosophy, 88, 209-225.

Sykes, B. (2001). The Seven Daughters of Eve: The Science that Reveals our Genetic Ancestry. New York: Norton.

Teller, P. (2001). Whither Constructive Empiricism? Philosophical Studies, 106, 123-150. van Fraassen, B. C. (1980). The Scientific Image. New York: Oxford University Press. van Fraassen, B. C. (1983). Glymour on Evidence and Explanation. In J. Earman (Ed.), Testing Scientific Theories (pp. 165-176). Minneapolis: University of Minnesota Press. van Fraassen, B. C. (1985). Empiricism in the Philosophy of Science. In P. M. Churchland \& C. A. Hooker (Eds.), Images of Science: Essays on Realism and Empiricism, with a Reply from Bas C. van Fraassen (pp. 245-308). Chicago: The University of Chicago Press. van Fraassen, B. C. (1989). Laws and Symmetry. Oxford: Clarendon Press. van Fraassen, B. C. (1994). Gideon Rosen on Constructive Empiricism. Philosophical Studies, 74, 179-192.

van Fraassen, B. (1998). The Agnostic Subtly Probabilified. Analysis, 58, 212-220. van Fraassen, B. C. (2000). The False Hopes of Traditional Epistemology. Philosophy and Phenomenological Research, 60, 253-280.

van Fraassen, B. C. (2001). Constructive Empiricism Now. Philosophical Studies, 106, 151-170. 
van Fraassen, B. C. (2002). The Empirical Stance. New Haven, CT: Yale University Press.

van Fraassen, B. C. (2007). From a View of Science to a New Empiricism. In B. Monton (Ed.), Images of Empiricism: Essays on Science and Stances, with a Reply from Bas C. van Fraassen (pp. 337-383). New York: Oxford University Press.

van Fraassen, B. C. (2010). Reply to Contessa, Ghins, and Healey. Analysis, 70, 547-556. 